\title{
Crystal Structures of Tcl1 Family Oncoproteins and Their Conserved Surface Features
}

\author{
John M. Petock ${ }^{1}$, Ivan Y. Torshin ${ }^{1}$, Yuan-Fang Wang ${ }^{1}$, Garrett C. Du Bois ${ }^{3}$, \\ Carlo M. Croce ${ }^{3}$, Robert W. Harrison ${ }^{2}$ and Irene T. Weber ${ }^{1, *}$ \\ ${ }^{1}$ Departments of Biology and Chemistry, Georgia State University, Atlanta, GA; \\ ${ }^{2}$ Department of Computer Science, Georgia State University, Atlanta, GA; ${ }^{3}$ Department \\ of Microbiology and Immunology, Kimmel Cancer Center, Thomas Jefferson University, \\ Philadelphia, PA \\ E-mail: biojmp@langate.gsu.edu; biotiy@asterix.cs.gsu.edu; bioyfw@langate.gsu.edu; \\ garrett.dubois@mail.tju.edu; carlo.croce@mail.tju.edu; rharrison@cs.gsu.edu; * iweber@gsu.edu
}

Received February 12, 2001; Revised May 9, 2002; Accepted May 13, 2002; Published July 4, 2002

Members of the TCL1 family of oncogenes are abnormally expressed in mature Tcell leukemias and B-cell lymphomas. The proteins are involved in the coactivation of protein kinase B (Akt/PKB), a key intracellular kinase. The sequences and crystal structures of three Tcl1 proteins were analyzed in order to understand their interactions with Akt/PKB and the implications for lymphocyte malignancies. Tcl1 proteins are $\sim 15 \mathrm{kD}$ and share $25-80 \%$ amino acid sequence identity. The tertiary structures of mouse Tcl1, human Tcl1, and Mtcp1 are very similar. Analysis of the structures revealed conserved semi-planar surfaces that have characteristics of surfaces involved in protein-protein interactions. The Tcl1 proteins show differences in surface charge distribution and oligomeric state suggesting that they do not interact in the same way with Akt/PKB and other cellular protein(s).

KEY WORDS: leukemia, oncoprotein, Tcl1, Akt/protein kinase B, X-ray crystallography

DOMAINS: bioinformatics, oncology, enzymology and protein-protein interaction, structural biology

\section{ROLE OF TCL1 IN LYMPHOCYTE MALIGNANCY}

The TCL1 family of oncogenes are abnormally expressed in mature T-cell leukemias and B-cell lymphomas[1,2]. This gene family includes human TCL1 (T-Cell Leukemia/lymphoma 1), TCL1b, and MTCP1 (Mature T-Cell Proliferation 1). Both TCL1 and TCL1b genes are found at 


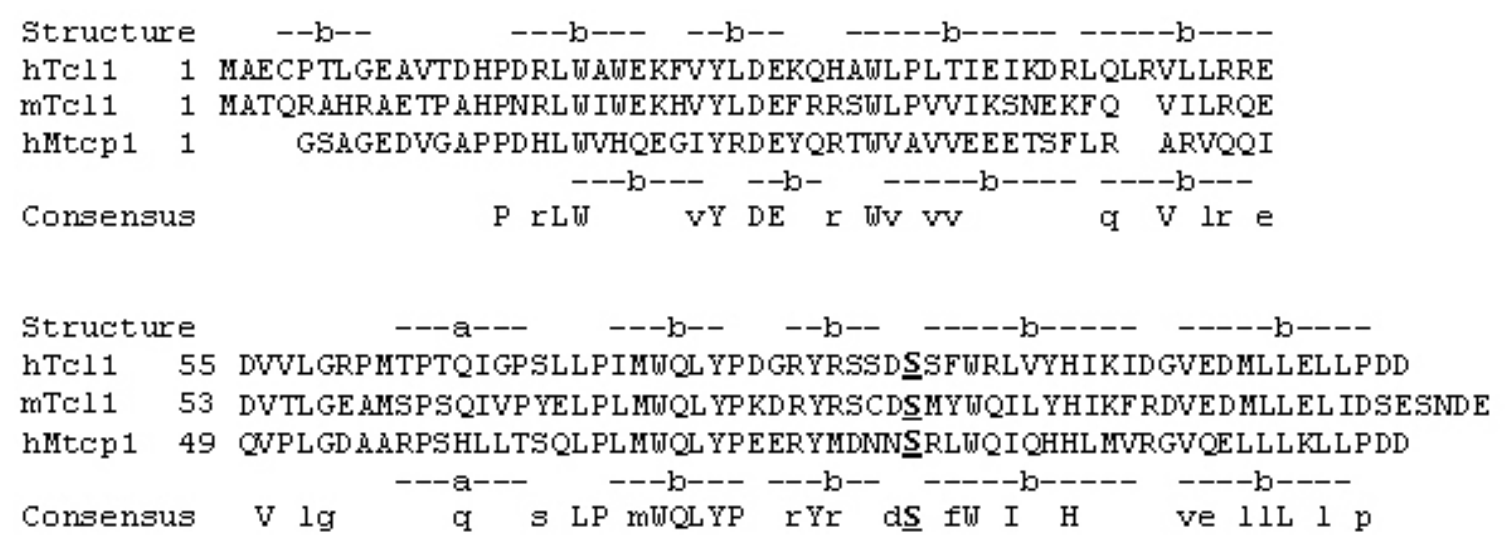

FIGURE 1. Sequence alignment of Tcl1 and Mtcp1 proteins. Sequences are shown for human Tcl1 (hTcl1), mouse Tcll (mTcl1), and human Mtcp1 (hMtcp1). The elements of secondary structure are shown for human Tcl1 and Mtcp1 with "a" indicating the short helix and "b" for beta strand. The conserved serine (Ser89 in human Tc11) is shown in bold.

the human TCL1 locus. TCL1 genes are expressed in embryonic tissues and immature B- and Tcells. Mature T-cells do not normally express TCL1 genes. Abnormal expression in mature lymphocytes is induced by chromosomal rearrangements that position the regulatory elements of T-cell receptor genes next to the TCL1 locus[2]. The TCL1 locus is activated in the majority of cases of T-cell prolymphocytic leukemia and T-cell chronic lymphocytic leukemia. Rearrangements involving MTCP1 are less commonly associated with mature T-cell leukemia. The oncogenic nature of TCL1 and MTCP1 has been confirmed by analysis of transgenic mouse models[3,4].

Members of the TCL1 family encode for $\sim 15-\mathrm{kD}$ proteins that share $25-80 \%$ amino acid sequence identity. The sequences of human Tcl1, mouse Tcl1, and Mtcp1 proteins are shown in Fig. 1. The normal physiological role of Tcll proteins is not well defined. Functional analysis revealed that Tcl1 proteins coactivate protein kinase $\mathrm{B}(\mathrm{Akt} / \mathrm{PKB})[5,6]$. No other protein is known to interact with Tcll proteins. Akt/PKB has a key role in diverse cellular processes including glucose metabolism, transcription, cell growth, survival, and migration[7]. Therefore, interactions between Tcl1 and Akt/PKB are likely to be important for the functioning of the whole cell. Akt/PKB is a serine/threonine kinase that comprises three functional domains: an $\mathrm{N}$ terminal pleckstrin homology $(\mathrm{PH})$ domain, a catalytic (kinase) domain, and a C-terminal regulatory domain. A Tcll dimer is proposed to bind to the $\mathrm{PH}$ domain forming an oligomeric complex with Akt/PKB, followed by Akt/PKB activation by other kinases. The activated Akt/PKB can phosphorylate many proteins involved in cell proliferation and survival. Therefore, abnormal coactivation of $\mathrm{Akt} / \mathrm{PKB}$ by $\mathrm{Tcl} 1$ in mature lymphocytes can lead to cancer.

\section{ANALYSIS OF TCL1 AND MTCP1 PROTEIN STRUCTURES}

The crystal structures were determined for the recombinant proteins human Tcll (PDB identifier 1JSG)[8], mouse Tcl1 (1JNP)[9], and human Mtcp1 (1A1X)[10]. These structures were determined at 2.0-2.5 $\AA$ resolution. The refinement parameters and statistics are summarized in Table 1. Whereas human Tcl1 and Mtcp1 were solved as monomers in the $I 222$ and $P 6_{2} 22$ space groups, respectively, the mouse Tcll crystal structure was solved as a dimer in the $C 2$ space 
TABLE 1

Crystallographic Statistics for Human Tcl1, Mouse Tcl1, and Human Mtcp1 Structures

\begin{tabular}{lccc}
\hline & Human Tcl1 & Mouse Tcl1 & Human Mtcp1 \\
\hline Space group & $I_{222}$ & $C_{1} 2_{1}$ & $P 6_{222}$ \\
Unit cell & $38.9,82.8,117.7$ & $89.3,115.9,37.9$ & $62.7,62.7,86.0$ \\
& $90.0^{\circ}, 90.0^{\circ}, 90.0^{\circ}$ & $90.0^{\circ}, 115.2^{\circ}, 90.0^{\circ}$ & $90.0^{\circ}, 90.0^{\circ}, 120^{\circ}$ \\
$R$ merge & 0.09 & 0.06 & 0.05 \\
Resolution & $2.5 \AA$ & $2.5 \AA$ & $2.0 \AA$ \\
$R$ factor & $19 \%$ & $23 \%$ & $21 \%$ \\
$R$ free & $26 \%$ & $24 \%$ & $25 \%$ \\
Bond length error & 0.006 & 0.02 & 0.007 \\
Angle error & 1.3 & 2.1 & 1.4 \\
\hline
\end{tabular}

TABLE 2

Structural Similarity for Mouse Tcl1, Human Tcl1, and Human Mtcp1

\begin{tabular}{lccccc}
\hline & Mouse Tcl1A & Mouse Tcl1B & Human Tcl1 & Human Mtcp1 & $\begin{array}{c}\text { Internal } \\
\text { Symmetry }\end{array}$ \\
\hline Mouse Tcl1A & - & $0.9(100 \%)$ & $0.6(50 \%)$ & $1.6(36 \%)$ & $1.3(12 \%)$ \\
Mouse Tcl1B & $0.9(100 \%)$ & - & $0.6(50 \%)$ & $1.5(36 \%)$ & $1.1(12 \%)$ \\
Human Tcl1 & $0.6(50 \%)$ & $0.6(50 \%)$ & - & $1.5(41 \%)$ & $1.3(13 \%)$ \\
Human Mtcp1 & $1.6(36 \%)$ & $1.5(36 \%)$ & $1.5(41 \%)$ & - & $1.7(13 \%)$ \\
\hline
\end{tabular}

Note: The crystal structure of mouse Tcl1 comprises the two subunits Tcl1A and Tcl1B.

* Root mean square (RMS) differences are given in Ångstroms with the percentage amino acid sequence identity in parentheses.

group. The three Tcll proteins show different possible subunit-subunit interfaces in the crystals. In solution, Mtcp1 is likely to be a monomer, while human Tcl1 can form dimers[11]. Moreover, mouse Tcll may form trimers in solution[6]. Therefore, the oligomeric state and subunit interface may differ among these proteins.

The crystal structures of mouse Tcl1, human Tcl1, and Mtcp1 have very similar tertiary structures as shown in Fig. 2A. However, no other similar structures were found in the Protein Data Bank[12]. The sequences and structures of Tcll proteins are compared in Table 2. Human and mouse Tcll structures have a root mean square (RMS) difference of $0.6 \AA$ for 100 superimposed $\mathrm{C} \alpha$ atoms and share 50\% sequence identity, while human Tcl1 and Mtcp 1 show $1.5 \AA$ RMS difference for $100 \mathrm{C} \alpha$ atoms and $41 \%$ sequence identity[10]. The structures of mouse Tc11 and human Mtcp1 have 1.6 ̊ RMS difference for 100 aligned $\mathrm{C} \alpha$ atoms. The proteins share an 8 -stranded beta barrel structure of unique topology. The beta barrel structure has a long surface loop with a short helical region that separates two 4-stranded pseudo-symmetric "half-barrel" structures (Fig. 2B). The three protein structures have high internal symmetry for the "halfbarrel” structure with RMS differences ranging from 1.1-1.7 $\AA$, despite the lack of significant sequence identity between the halves (12-13\%). 


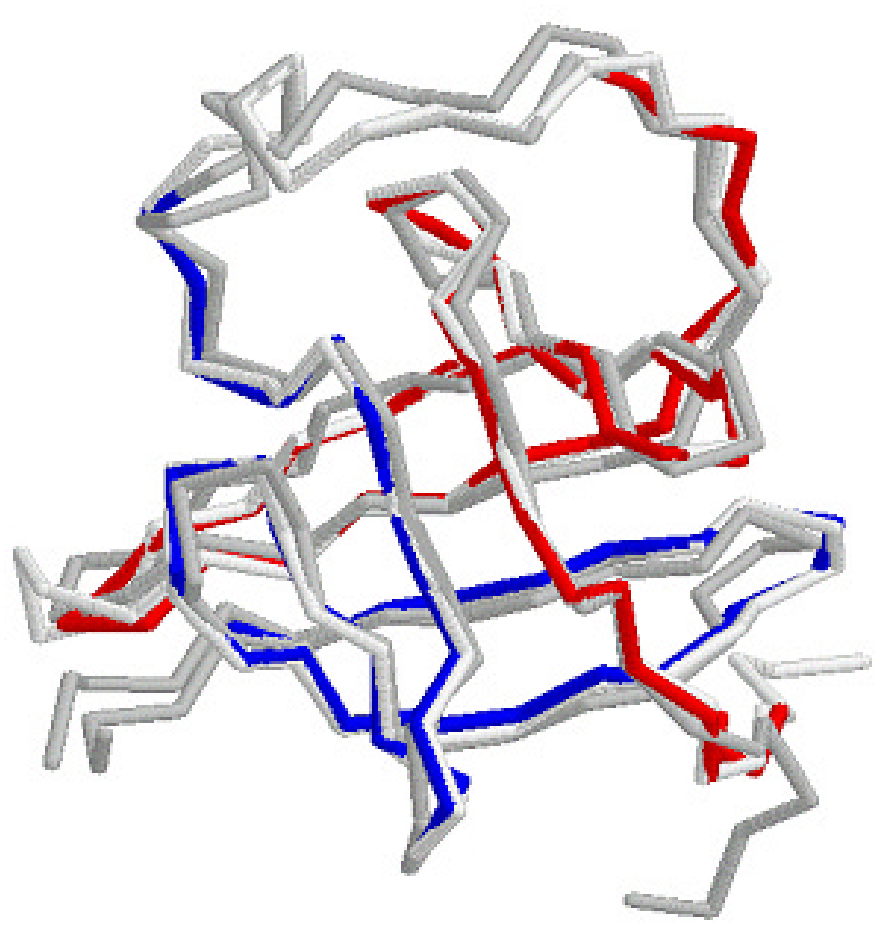

FIGURE 2a.

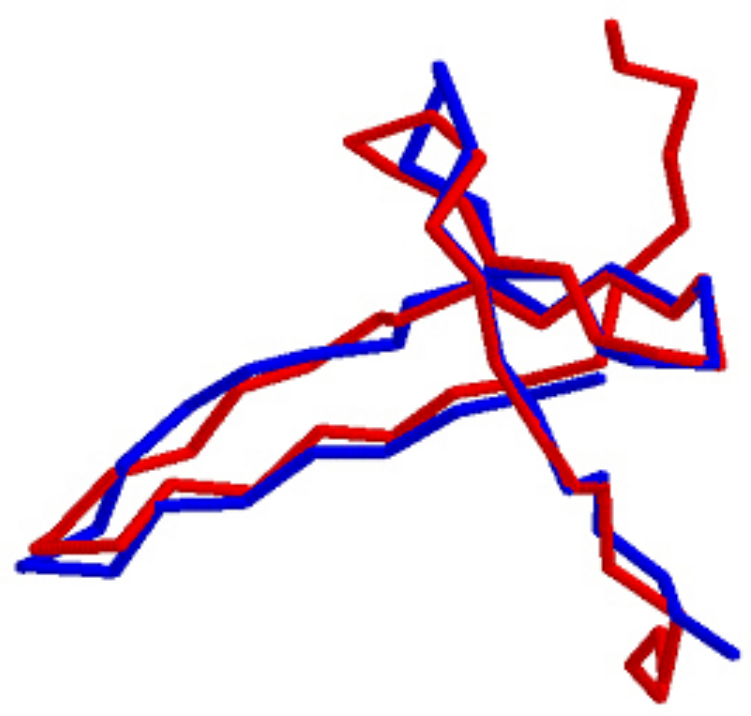

FIGURE 2b.

FIGURE 2. Superposition of alpha carbon backbone atoms of the Tcl1 family members: mouse Tcl1 (red for residues 8-57, blue for 67-108), human Tcl1 (white), and human Mtcp1 (gray). The red/blue color scheme is shown to emphasize the half-barrel structure shown in (B). Two tandem halves of mouse Tcl1 structure superimposed to show the internal symmetry (B). Residues 8-57 (red) and 67-108 (blue) are included. 

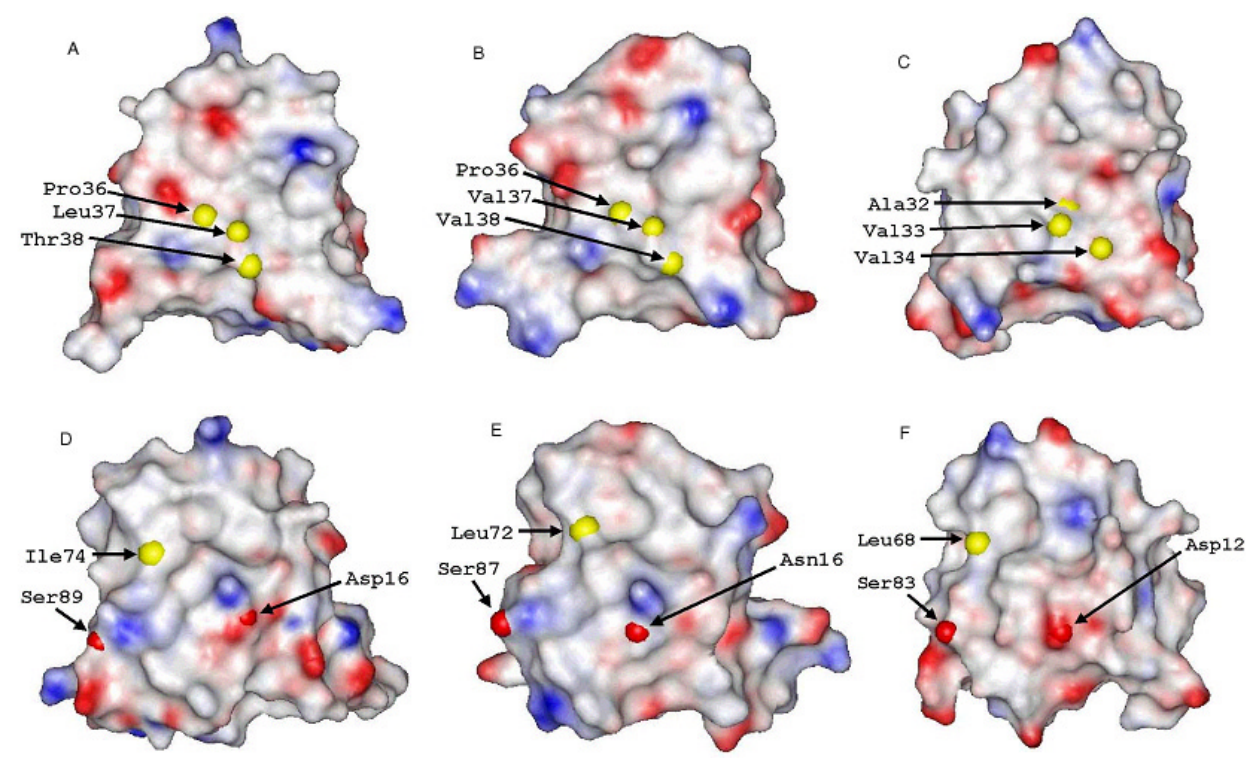

FIGURE 3. The largest conserved semi-planar surfaces of the Tcl1 protein members is shown with the surface charge distribution for: (A) human Tcl1, (B) mouse Tcl1, and (C) human Mtcp1. Blue indicates positive charge distribution and red indicates negative. The human Tcl1 residues Pro36, Leu37, and Thr38 found to be important for dimer formation are shown and equivalent residues are indicated in the other proteins. The Tcl1 surfaces proposed to interact with Akt/PKB are shown for: (D) human Tcl1, (E) mouse Tcll, and (F) human Mtcp1. This surface is located opposite to the dimer surface shown in views A-C. The conserved serine is indicated. Human Tc11 Asp16 and Ile74 found to be important for interactions with Akt are shown in D, and the equivalent residues in mouse Tcl1 and Mtcp1 are indicated in E and F. The surface pictures were generated with the program WebLab ViewerLite[16] using a probe radius of $2.5 \AA$.

\section{ANALYSIS OF TCL1 PROTEIN SURFACES}

Human Tcl1 residues involved in homodimer formation and association with Akt/PKB have been identified recently[13]. Mutational analysis of human Tcl1 suggested that amino acids 35-37 are involved in dimer formation, while residues Asp16 and Ile74 are important for Tcl1-Akt/PKB interactions. It is not known whether the equivalent residues in mouse Tcll and human Mtcp1 have the same function. Presumably, additional Tcll residues are involved in these proteinprotein interactions. Therefore, the molecular surfaces of Tcl1 and Mtcpl structures were analyzed in relation to the human Tcll mutations. The Tcll proteins show three conserved nearly planar surfaces[10]. These large surfaces have characteristic features with many "knobs" and "clefts" similar to the interfaces observed in homodimers and other protein-protein complexes[14,15]. The Tcl1 mutations that interfere with dimer formation and interactions with Akt/PKB lie on two of these large surfaces.

The human Tcl1 residues 36-38 that were shown to be involved in dimer formation[13] lie on the largest of the conserved semi-planar surfaces of Tcll proteins. The proposed Tcll dimerforming surface is roughly $500 \AA^{2}$ in size and is shown in Fig. 3A-C. However, the surface distribution of negative and positive charges is different in each of the Tcll proteins. We identified the surface accessible residues comprising this dimer interface in all three Tcll crystal structures (Table 3). These residues are Glu22, Leu35, Leu37, Thr38, Ile39, Glu40, Ile41, Lys42, Leu50, Arg52, Glu54, Val56, Val57, Arg60, Thr63, Gln66, Pro69, Ser70, Leu71, Ile100, Asp101, and Val103 in human Tcl1 (identical residues in bold, similar residues in italics). Only 2 out of 22 surface residues are identical and 3 are similar in all three proteins $(23 \%$ [5/22] conserved residues). Thus, the majority of residues forming this surface differ among the Tcl1 proteins. 
TABLE 3

Comparison of Surface Residues for Human Tcl1, Mouse Tcl1, and Human Mtcp1 Proteins

\begin{tabular}{llllll}
\hline \multicolumn{3}{c}{ Akt-Interacting } & Surface & \multicolumn{3}{c}{ Dimer Forming Surface } \\
\hline Human & Mouse & Human & Human & Mouse & Human \\
Tcl1 & Tcl1 & Mtc1 & Tcl1 & Tcl1 & Mtcp1 \\
Asp16 & Asn16 & Asp12 & Glu22 & Glu22 & Gln18 \\
Arg17 & Arg17 & His13 & Leu35 & Leu35 & Val31 \\
Trp19 & Trp19 & Trp15 & Leu37 & Val37 & Val33 \\
Trp21 & Trp21 & His17 & Thr38 & Val38 & Val34 \\
Glu29 & Glu29 & Glu25 & lle39 & Ile39 & Glu35 \\
Lys30 & Phe30 & Tyr26 & Glu40 & Lys40 & Glu36 \\
Gln31 & Arg31 & Gln27 & Ile41 & Ser41 & Glu37 \\
Arg60 & Glu58 & Asp54 & Lys42 & Asn42 & Thr38 \\
Pro61 & Ala59 & Ala55 & Leu50 & Ile48 & Arg44 \\
Thr63 & Ser61 & Arg57 & Arg52 & Arg50 & Gln46 \\
Pro64 & Pro62 & Pro58 & Glu54 & Glu52 & Ile48 \\
Ile74 & Leu72 & Leu68 & Val56 & Val54 & Val50 \\
Met75 & Met73 & Met69 & Val57 & Thr55 & Pro51 \\
Gln77 & Gln75 & Gln71 & Arg60 & Glu58 & Asp54 \\
Tyr79 & Tyr77 & Tyr73 & Thr63 & Ser61 & Arg57 \\
Pro80 & Pro78 & Pro74 & Gln66 & Gln64 & His60 \\
Asp81 & Lys79 & Glu75 & Pro69 & Pro67 & Thr63 \\
Arg83 & Arg81 & Arg77 & Ser70 & Tyr68 & Ser64 \\
Arg85 & Arg83 & Met79 & Leu71 & Glu69 & Gln65 \\
Ser87 & Ala85 & Asn81 & Ile100 & Phe98 & Val94 \\
Asp88 & Asp86 & Asn82 & Asp101 & Arg99 & Arg95 \\
Ser89 & Ser87 & Ser83 & Val103 & Val101 & Val97 \\
Ser90 & Met88 & Arg84 & & & \\
\hline & & & & & \\
\hline
\end{tabular}

The molecular surface of human Tcl1 that interacts with Akt/PKB can be identified from the two residues Asp16 and Ile74 that were shown to be important for Tcl1-Akt/PKB interactions[13]. The tentative $\mathrm{Akt} / \mathrm{PKB}$ binding surface of $\mathrm{Tcll}$ corresponds to another conserved semi-planar region in the structures of human Tcl1, mouse Tcl1, and human Mtcp1, as shown in Fig. 3D-F. The surface accessible residues on the proposed Akt/PKB binding surface of human Tcl1 are Asp16, Arg17, Trp19, Trp21, Glu29, Lys30, Gln31, Arg60, Pro61, Thr63, Pro64, Ile74, Met75, Gln77, Tyr79, Pro80, Asp81, Arg83, Arg85, Ser87, Asp88, Ser89, and Ser90 (identical residues in bold, similar residues in italics). These 23 residues are likely to be important for interacting with Akt/PKB in the three Tcl1 proteins. Out of 23 residues forming the surface, 9 are identical and 4 are similar residues, suggesting a higher degree of conservation than in the putative dimer interface described above (52\% [13/23] compared to $23 \%)$. Interestingly, the residues Asp16 and Ile74 shown to be important for interactions with Akt/PKB are not identical in all three proteins. Like the largest semi-planar surface of Tcll proteins, the charge distributions of the interacting surfaces differ among the three proteins. This suggests that different Tcll proteins do not bind in an identical way to Akt/PKB. Indeed, a difference in affinity for Akt/PKB was observed in studies with Tcl1, Tcl1b, and Mtcp1[5,6]. The activation of 
Akt/PKB by interaction with Tcl1 was tenfold higher than that of Mtcp1. In addition, the three isoforms of Akt/PKB differ in their specificity for Tcl1 oncoproteins; isozyme Akt3/PKB- $\gamma$ is most specific for Tcl1[18].

The potential phosphorylation sites differ for Tcl1 proteins[7]. Mouse Tcl1 shows a potential CK2 phosphorylation site at residues 55-58 on the dimer interface and a potential site for tyrosine kinase phosphorylation at residues 83-89 on the putative Akt/PKB interacting surface. No known phosphorylation sites were found in the Mtcpl sequence. These differences in the location and the types of potential phosphorylation sites in relation to the molecular surfaces suggest that the three Tcll proteins interact with different cellular kinases.

\section{IMPLICATIONS FOR TCL1 INTERACTIONS WITH AKT/PKB}

The overall coactivation of Akt/PKB by Tcl1 appears to be a complex process[5,6,13,19,20,21]. Initially, a growth factor signal activates cell surface receptors and causes phosphoinositide 3kinase (PI3K) to produce phosphoinositides. These products bind to the PH domain of Akt/PKB for its recruitment to the plasma membrane. Next, a Tcll dimer binds to the PH domain of Akt/PKB forming large Tcl1-Akt/PKB complexes of unknown stoichiometry. Then, Akt/PKB is phosphorylated by PDK (3-phosphoinositide-dependent protein kinase 1) at Thr308 and at Ser473 by an unknown kinase. Once activated, Akt/PKB phosphorylates its downstream targets in the cytoplasm and possibly in the nucleus.

Our analysis of Tcll proteins has suggested another possible type of interaction with $\mathrm{Akt} / \mathrm{PKB}$. The consensus sequence for Akt/PKB phosphorylation is reported to be RxR-x(2)[ST][22]. Human Tcl1, Mtcp1, and mouse Tcll show only one conserved and solvent accessible serine (Ser89 in human Tcl1) in the turn between beta strands 6 and 7 (Fig. 1 and 3). This conserved serine is also present in human Tcllb. The sequence around the conserved serine has the pattern of RxR-x(3)-S in human and mouse Tcl1 and RxM-x(3)-S in Mtcp1 (Fig. 1). The sequence in Tcl1 resembles the consensus pattern for Akt/PKB phosphorylation, although there is an extra residue between the conserved RxR and S. However, the sequence consensus of a phosphorylation site can be degenerate. For example, a tyrosine kinase can phosphorylate sequences of different consensus patterns such as [RK]-x(2)-[DE]-x(3)-Y or [RK]-x(3)-[DE]$\mathrm{x}(2)-\mathrm{Y}(23 ; 24)$. Therefore, it is possible that Akt/PKB can phosphorylate the conserved serine in the Tcl1 proteins. Alternately, the $\mathrm{Rx}[\mathrm{RM}]-\mathrm{x}(3)-\mathrm{S}$ region may act as a substrate analog of Akt/PKB. The importance of the conserved Ser89 in human Tcl1 is consistent with its location being on the Akt/PKB interacting surface about 16 and $11 \AA$ from the residues Asp16 and Ile74, respectively (Fig. 3D).

Because Akt/PKB is important for proliferation and survival of lymphocytes, abnormal coactivation by Tcll in mature lymphocytes can lead to malignancies. Differences in the oligomeric form, subunit interface, surface accessible residues, and potential phosphorylation sites between Tcl1 and Mtcp1 proteins are likely to contribute to the tenfold differences[5,6] in their interactions with Akt/PKB. Hence, despite the highly conserved tertiary structures of the Tcl1 proteins, each Tcl1 family member may interact with different cellular proteins. These interacting proteins may be different isoforms of $\mathrm{Akt} / \mathrm{PKB}$ or other unidentified proteins. Presently, only a few of the Tcll residues important for interactions with Akt/PKB have been experimentally defined. Further analysis is needed to fully define the interacting residues in the Tcl1-Akt/PKB complexes as well as the stoichiometry of such complexes. This review provides a rationale for more detailed mutational analysis of the Tcl1 proteins. 


\section{ACKNOWLEDGEMENTS}

This work was supported by the National Cancer Institute grant CA76259. J.M.P. was supported in part by the Georgia State University Research Program Enhancement grant.

\section{REFERENCES}

1. Stern, M.H., Soulier, J., Rosenzwajg, M., Nakahara, K., Canki-Klain, N., Aurias, A., Sigaux, F., and Kirsch, I.R. (1993) MTCP-1: a novel gene on the human chromosome Xq28 translocated to the T cell receptor alpha/delta locus in mature T cell proliferations. Oncogene 8, 2475-2483.

2. Virgilio, L., Isobe, M., Narducci, M.G., Carotenuto, P., Camerini, B., Kurosawa, N., Abbas-ar-Rushdi, Croce, C.M., and Russo, G. (1993) Chromosome walking on the TCL1 locus involved in T-cell neoplasia. Proc. Natl. Acad. Sci. U. S. A. 90, 9275-9279.

3. Gritti, C., Dastot, H., Soulier, J., Janin, A., Daniel, M.T., Madani, A., Grimber, G., Briand, P., Sigaux, F., and Stern, M.H. (1998) Transgenic mice for MTCP1 develop T-cell prolymphocytic leukemia. Blood 92(2), 368-373.

4. Virgilio, L., Lazzeri, C., Bichi, R., Nibu, K.I., Narducci, M.G., Russo, G., Rothstein, J., and Croce, C.M. (1998) Deregulated expression of TCL1 causes T cell leukemia in mice. Proc. Natl. Acad. Sci. U. S. A. 95, 3885-3889.

5. Pekarsky, Y., Koval, A., Hallas, C., Bichi, R., Tresini, M., Malstrom, S., Russo, G., Tsichlis, P., and Croce, C.M. (2000) Tcll enhances Akt kinase activity and mediates its nuclear translocation. Proc. Natl. Acad. Sci. U. S. A. 97, 3028-3033.

6. Laine, J., Künstle, G., Obata, T., Sha, M., and Noguchi, M. (2000) The protooncogene TCL1 is an Akt kinase coactivator. Mol. Cell. 6, 395-407.

7. Brazil, D.P. and Hemmings, B.A. (2001) Ten years of protein kinase B signaling: a hard Akt to follow. TRENDS Biochem. Sci. 26(11), 657-664.

8. $\quad$ Hoh, F., Yang, Y.S., Guignard, L., Padilla, A., Stern, M.H., Lhoste, J.M., and van Tilbeurgh, H. (1998) Crystal structure of p14TCL1, an oncogene product involved in T-cell prolymphocytic leukemia, reveals a novel beta-barrel topology. Structure 6, 147-155.

9. Fu, Z.Q., Du Bois, G.C., Song, S.P., Kulikovskaya, I., Virigilio, L., Croce, C.M., Weber, I.T., and Harrison, R.W. (1998) Crystal structure of MTCP-1: implications for role of TCL-1 and MTCP-1 in T cell malignancies. Proc. Natl. Acad. Sci. U. S. A. 95, 3413-3418.

10. Petock, J.M., Torshin, I.Y., Wang, Y.F., Dubois, G.C., Croce, C.M., Harrison, R.W., and Weber, I.T. (2001) Structure of mouse Tcl1 at $2.5 \AA$ resolution and implications for the TCL oncogene family. Acta Crystallogr., Sect. D 57, 1545-1551.

11. Du Bois, G.C., Song, S.P., Kulikovskaya, I., Virgilio, L., Varnum, J., Germann, M.W., and Croce, C.M. (1998) Purification and characterization of recombinant forms of TCL-1 and MTCP-1 proteins. Protein Expr. Purif. 12, 215-225.

12. Berman, H.M., Westbrook, J., Feng, Z., Gilliland, G., Bhat, T.N., Weissig, H., Shindyalov, I.N., and Bourne, P.E. (2000) The Protein Data Bank. Nucleic Acids Res. 28, 235-242. http://www.rcsb.org/.

13. Künstle, G., Laine, J., Pierron, G., Kagami, S.S., Nakajima, H., Hoh, F., Roumestand, C., Stern, M.H., and Noguchi, M. (2002) Identification of Akt association and oligomerization domains of the Akt kinase coactivator TCL1. Mol. Cell. Biol. 22(5), 1513-1525.

14. Laskowski, R.A., Luscombe, N.M., Swindells, M.B., and Thorton, J.M. (1996) Protein clefts in molecular recognition and function. Protein Sci. 12, 2438-2452.

15. Norel, R., Lin, S.L., Wolfson, H.J., and Nussinov, R. (1994) Shape complementarity at protein-protein interfaces. Biopolymers 7, 933-940.

16. Molecular Simulations Inc. MSI WebLab Viewer Lite. 9685 Scranton Road, San Diego, CA 92121, (858) 458-9990, Fax: (858) 458-0136.

17. Torshin, I. (1999) Molecular surface sequence analysis of several E. coli enzymes and implications for existence of casein kinase-2 bacterial predecessor. Front. Biosci. 4, D394-407.

18. Laine, J., Künstle, G., Obata, T., and Noguchi, M.J. (2002) Differential regulation of Akt kinase isoforms by the members of the TCL1 oncogene family. J. Biol. Chem. 277, 3743-3751.

19. Bellacosa, A., Chan, T.O., Ahmed, N.N., Datta, K., Malstrom, S., Stokoe, D., McCormick, F., Feng, J., and Tsichlis, P. (1998) Akt activation by growth factors is a multiple-step process: the role of the PH domain. Oncogene 17(3), 313-325.

20. Stephens, L., Anderson, K., Stokoe, D., Erdjument-Bromage, H., Painter, G.F., Holmes, A.B., Gaffney, P.R., Reese, C.B., McCormick, F., Tempst, P., Coadwell, J., and Hawkins, P.T. (1998) Protein kinase B kinases that mediate phosphatidylinositol 3,4,5-trisphosphate-dependent activation of protein kinase B. Science 279(5351), 710-714. 
21. Pekarsky, Y., Hallas, C., and Croce, C.M. (2001) Molecular basis of mature T-cell leukemia. JAMA 286(18), 2308-2314.

22. Obata, T., Yaffe, M.B., Leparc, G.G., Piro, E.T., Maegawa, H., Kashiwagi, A., Kikkawa, R., and Cantley, L.C. (2000) Peptide and protein library screening defines optimal substrate motifs for AKT/PKB. J. Biol. Chem. 275(46), 36108-36115.

23. Falquet, L., Pagni, M., Bucher, P., Hulo, N., Sigrist, C.J., Hofmann, K., Bairoch, A. (2002) The PROSITE database, its status in 2002. Nucleic Acids Res. 30, 235-238.

24. Hofmann, K., Bucher, P., Falquet, L., and Bairoch, A. (1999) PROSITE data base UI - 99063695, and (1999) The PROSITE database, its status in 1999. Nucleic Acids Res. 27(1), 215-219.

\section{This article should be referenced as follows:}

Petock, J.M., Torshin, I.Y., Wang, Y-F., Du Bois G.C., Croce, C.M., Harrison, R.W., and Weber, I.T. (2002) Crystal structures of Tcl1 family oncoproteins and their conserved surface features. TheScientificWorldJOURNAL 2, 18761884 .

\section{Handling Editor:}

Pierre Kremers, Associate Editor for Enzymology and Protein-Protein Interaction - a domain of TheScientificWorldJOURNAL. 

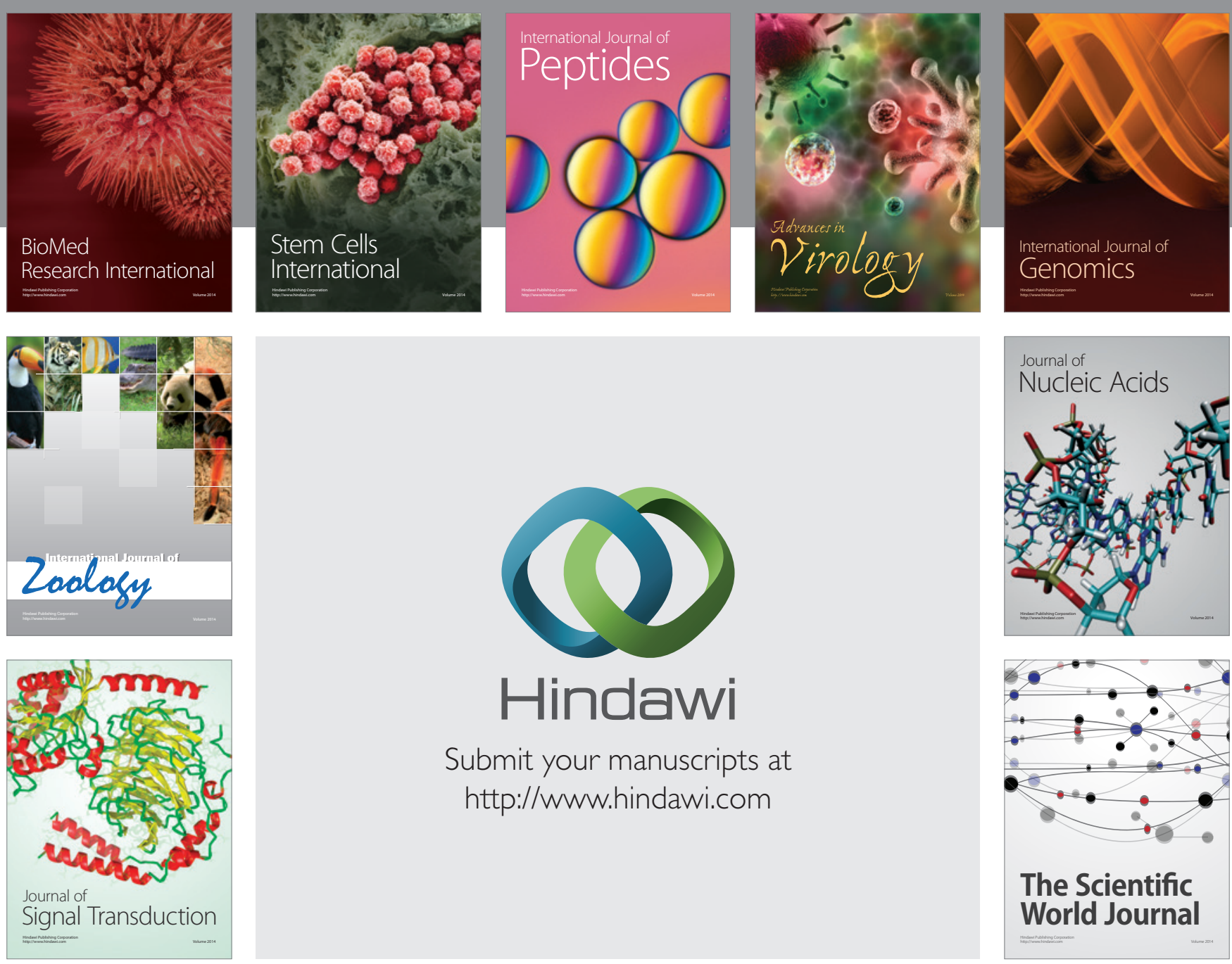

Submit your manuscripts at

http://www.hindawi.com
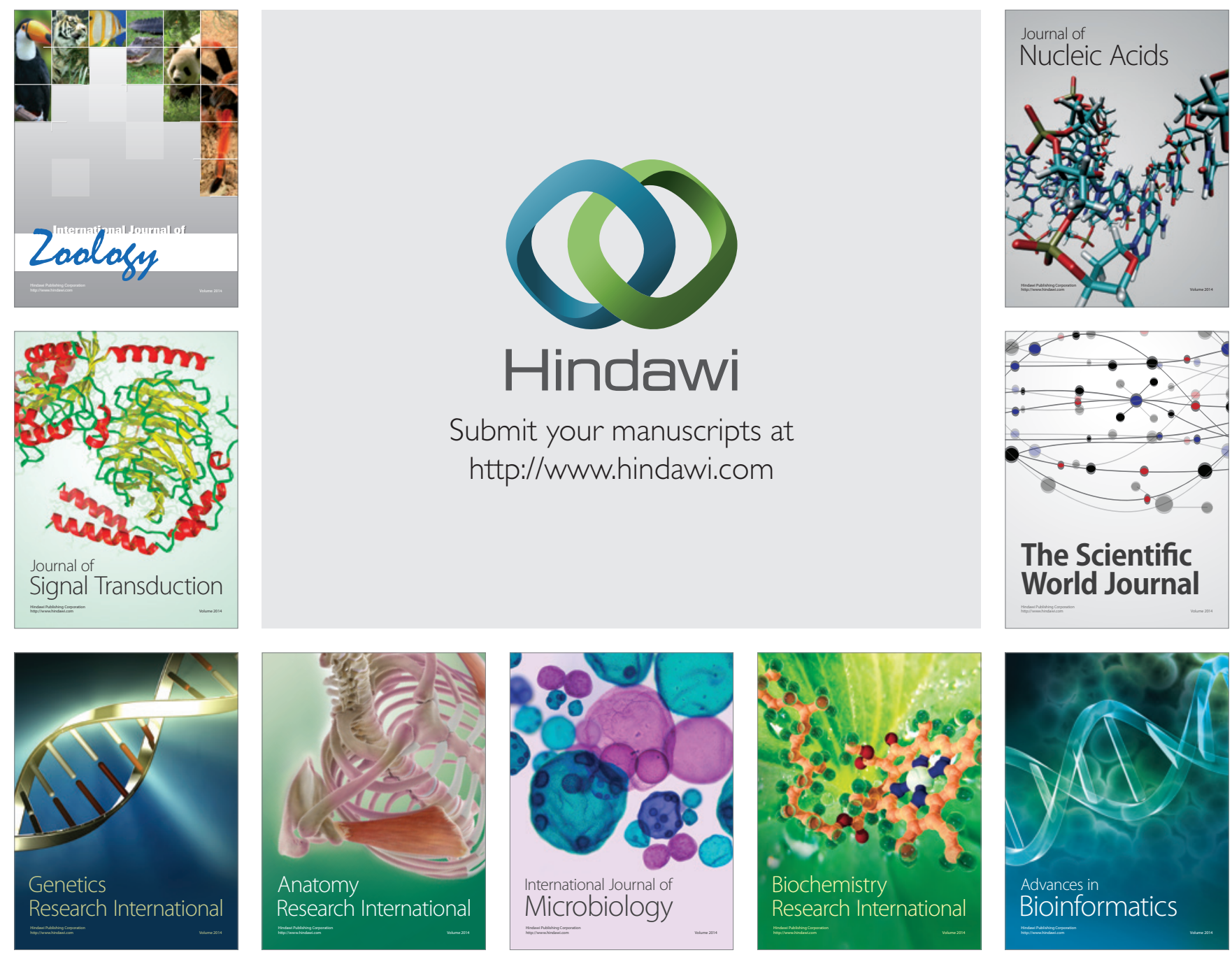

The Scientific World Journal
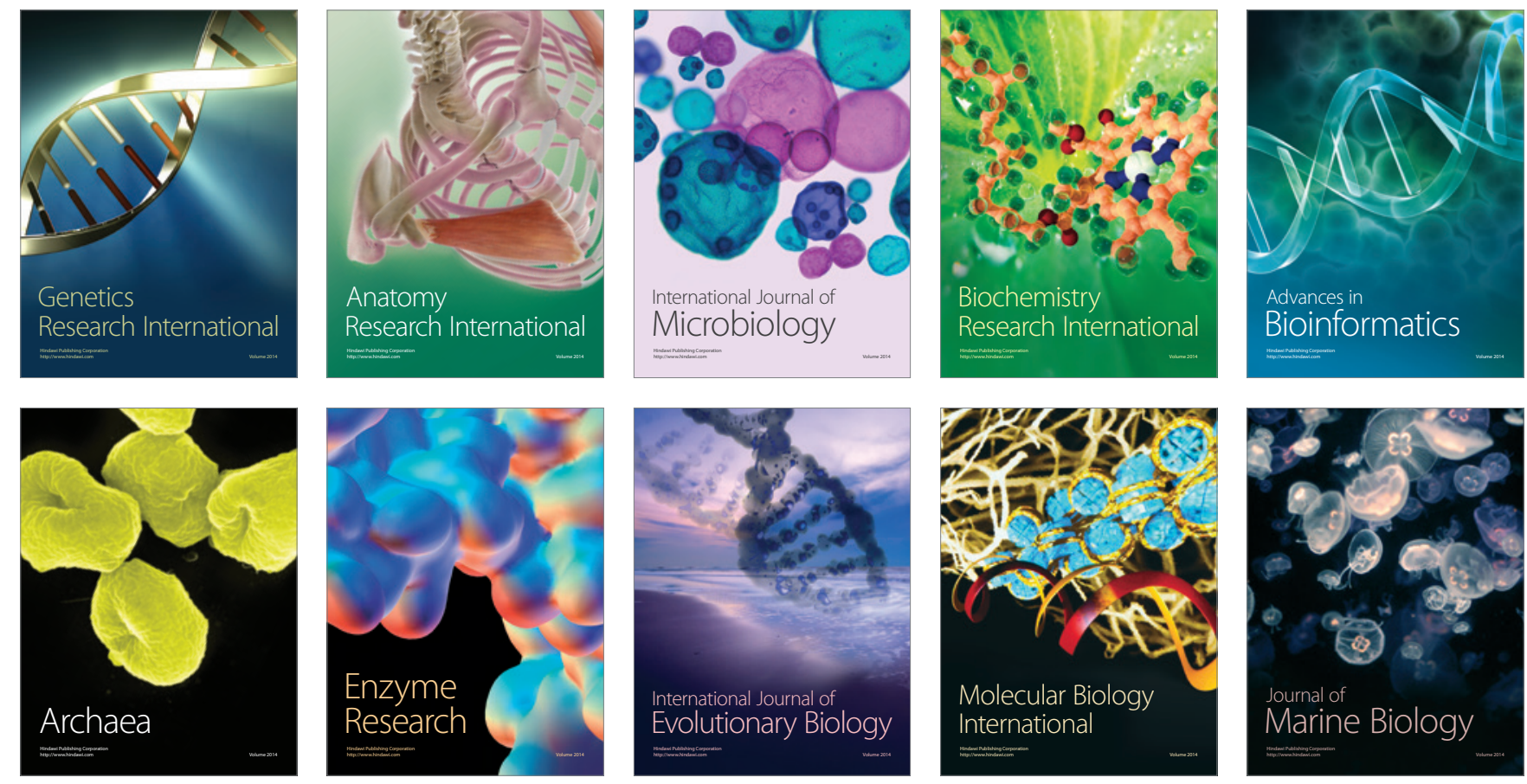